Original Article

\title{
IN VIVO ANTI-DIABETIC ACTIVITY EVALUATION OF THE BARK OF CASCABELA THEVETIA L. IN STREPTOZOTOCIN INDUCED DIABETIC RATS
}

\author{
NEELUTPAL GOGOIa,b* , BIMAN BHUYAN ${ }^{b}$ \\ aSrikrupa Institute of Pharmaceutical Sciences, Vellikata, Telengana, India, bDepartment of Pharmaceutical Sciences, Dibrugarh \\ University, Dibrugarh, Assam, India, Pin 786004 \\ Email: neelutpalg@gmail.com
}

Received: 20 Jan 2017 Revised and Accepted: 20 Apr 2017

\begin{abstract}
Objective: In this study, the plant Cascabela thevetia L. was selected based on ethnomedicinal documentation reports for evaluation of the antidiabetic activity. The aim of this study was to carry out acute toxicity study and in vivo evaluation of antidiabetic activity in an animal model.

Methods: Firstly direct extraction of the dried bark powder was done with methanol using soxhlet apparatus. After collecting the extract, acute toxicity study was performed according to OECD (Organization for Economic Cooperation and Development) guideline 425. For in vivo evaluation of antidiabetic activity, streptozotocin (STZ) and nicotinamide induced type 2 diabetic male rat model was used. Six groups containing six animals in each were taken for the in vivo study and marked as normal control, standard control, negative control and test controls. For all the animals body weight, body temperature, blood glucose levels were determined at an interval of $5 \mathrm{~d}$. After $15 \mathrm{~d}$ of treatment different biochemical parameters like triglyceride, cholesterol, high-density lipoprotein (HDL), low-density lipoprotein (LDL), alkaline phosphatase level (ALP), serum glutamic oxaloacetic transaminase (SGOT), serum glutamic pyruvic transaminase (SGPT), total protein were determined and the results were evaluated by statistically using one-way analysis of variance (ANOVA). On the $15^{\text {th }}$ day, all the animals were sacrificed and histopathological study of pancreases tissue was done.
\end{abstract}

Results: The effects of the test extracts in lowering the blood glucose level and maintaining other biochemical parameters in the test groups were compared with the effect of standard drug metformin hydrochloride, $10 \mathrm{mg} / \mathrm{kg}$ body weight treated group and negative control group. The data were statistically evaluated using one-way analysis of variance (ANOVA) followed by Dunnet comparison all vs control method and taking significant at $\mathrm{p}<0.01$. By comparing different biochemical parameters and histoarchitecture of the different test groups of animals, it was found that group V treated with $200 \mathrm{mg} / \mathrm{kg}$ body weight shows a significant effect.

Conclusion: After performing the experiment it was found that the bark of Cascabela thevetia L. has the potential for blood glucose lowering activity and able to control abnormal lipids and enzymes level in blood. Further isolation of the compounds can lead to finding out the exact compound responsible for the activity.

Keywords: Antidiabetic activity, Cascabela thevetia L., Streptozotocin, Type 2 diabetes, In vivo study

(C) 2017 The Authors. Published by Innovare Academic Sciences Pvt Ltd. This is an open access article under the CC BY license (http://creativecommons.org/licenses/by/4.0/) DOI: http://dx.doi.org/10.22159/ijpps.2017v9i6.17200

\section{INTRODUCTION}

Diabetes is a metabolic disorder initially characterized by a loss of glucose homeostasis with disturbances of carbohydrate, fat and protein metabolism resulting from defects in insulin secretion, insulin action or both [1]. The pathogenesis of diabetes mellitus is managed by insulin and oral administration of hypoglycemic drugs such as sulphonylureas and biguanides [2]. Apart from having a number of side effects, the oral synthetic hypoglycemic agents have not been able to maintain euglycemia and to control long-term microvascular and macrovascular complications [3]. Due to toxicity and side effects of oral antidiabetic agents available, use of herbal medicines for the treatment of diabetes has gained importance throughout the world [4]. The World Health Organization also recommended and encouraged the practice of herbal medicine especially in countries where access to the conventional treatment of diabetes is not adequate [5]. The available literature shows that there are more than 400 plant species having hypoglycemic activity [6]. Though some of these plants have a great reputation in the indigenous systems of medicine for their antidiabetic activities, many remain to be scientifically established.

"Halodhiya karabi" (Cascabela thevetia L.) is a shrub or small tree grown as an ornamental plant in America, Africa, Asia, Malaysia and Pacific islands. It is reported that the dried bark powder of Cascabela thevetia L. is used for the treatment of diabetes [7]. N. Srivastava et al. (2009) has shown the comparative antioxidant activities of different parts like stem, flower, and leaf of Cascabela thevetia L. [8]. In this study, the methanol extract was selected for evaluation of antidiabetic activity on streptozocin-induced diabetic rats. The extract was selected based on the yield and number of phytoconstituents present in it which was found from the preliminary phytochemical investigations. For evaluation of antidiabetic activity fasting blood glucose level (FBG) and lipid biochemical parameters were investigated. Finally, the histopathological study of the pancreas tissues was performed.

\section{MATERIALS AND METHODS}

Plant materials

Barks of the Cascabela thevetia L. were collected from Longpotia, Sivasagar, Assam, India during the month of July, 2014. The plant was identified and authenticated by Dr. A. A. Mao, Scientist-E, Botanical Survey of India, Eastern Regional Centre, Shillong via letter of reference no. BSI/ERC/Tech/Identification/2014/361 on 26 August 2014. After collection, barks were cleaned properly, cut into small pieces and dried under shade for two weeks. The dried barks were pulverized in a mechanical grinder to a coarse powder and stored in an airtight container free from moisture for future work.

\section{Chemicals and diagnostic kits}

Methanol (HiMedia Laboratories), streptozotocin (Sisco Research Laboratories), metformin hydrochloride (Sigma-Aldrich Chemical Company), one-touch glucometer accusure (Microgene Diagnostic Systems Pvt. Ltd.), gluco check strips (Rapid Diagnostics Group of Companies), ALP mono-reagent kit, cholesterol kit (Beacon Diagnostics Pvt. Ltd.), SGPT kit, SGOT kit (Medsource Ozone Biomedicals Pvt. Ltd.), triglyceride kit (Synergy Bio: A division of Euro-Diagnostic Systems Pvt. Ltd.) and total protein kit (Span Diagnostic Ltd.) were used in this study. 


\section{Preparation of methanolic extract}

$200 \mathrm{~g}$ of the powdered crude drug of Cascabela thevetia L. (FamilyApocynaceae) bark were extracted by continuous hot extraction using soxhlet apparatus with $1000 \mathrm{ml}$ of methanol for about $18 \mathrm{~h}$ maintaining the temperature in between $55-65^{\circ} \mathrm{C}$. Here continuous hot extraction was preferred over cold maceration technique to get maximum quantity of yield. The extract was concentrated by rotary evaporator and later solvent was recovered. The yield was found to be $14.6 \% \mathrm{w} / \mathrm{w}$ of the initial weight. Phytochemical screening of the extract gave an idea regarding the presence of important plant secondary metabolites like alkaloid, flavonoid, triterpenoid, tannin and phytosterol.

\section{Acute oral toxicity study}

Acute toxicity study was carried out as per internationally accepted protocol drawn under OECD guideline 425 in Wistar albino female rats. The animals were fasted overnight prior to dosing. The extract was administered in a single dose by feeding needle. As the information about the toxicity of the test extract was gained from a previous study of fruit extract of Cascabela thevtia L. so limit test was performed [9]. In the limit test, one animal was administered at a time with a dose of $2000 \mathrm{mg} / \mathrm{kg}$ body weight. As the first animal was survived after $48 \mathrm{~h}$, additional two animals were administered at the same dose and observed. These two animals were also survived and hence the experiment was stopped. During the study other toxicological symptoms like behavioral pattern change, salivation, sleep, lethargy, diarrhea etc. The animals were further kept under daily observation for $21 \mathrm{~d}$ with proper care. As per calculations from acute oral toxicity (guideline 425) statistical program (version 1.0), the $\mathrm{LD}_{50}$ value of Cascabela thevetia $\mathrm{L}$. bark extract was found to be more than $2000 \mathrm{mg} / \mathrm{kg}$ body weight.

\section{Animals and experimental design}

Male albino rats Wistar strain and weighing about 100-120 g were obtained from M/S Chakraborty Enterprise, Kolkata and used for the in vivo antidiabetic activity study. The required approval for performing the animal study was acknowledged from the Institutional Animal Ethical Committee, Dibrugarh University, vide registration number-1576/GO/a/11/CPCSEA Dated: 17/2/2012 and approval number-1AEC/DU/87 dtd. 27/3/2015. The animal house was well ventilated and maintained at room temperature $25 \pm 2{ }^{\circ} \mathrm{C}$, $30-35 \%$ relative humidity, and $12 \mathrm{~h}$ dark/light cycle. The animals were housed in large spacious hygienic cages during the course of the experimental period and well provided with pellet diet and water ad libitum. Prior to the experimental study, animals were fasted by depriving them of food for $16 \mathrm{~h}$ but allowing for free access to water. The place of the experiment was kept hygienic by cleansing with an antiseptic solution, and further procedures involving the care of animals were conducted in conformity with the institutional guidelines.

\section{Induction of experimental diabetes}

In experimental animals, diabetes was induced by intraperitoneal (i.p.) injection of nicotinamide $(230 \mathrm{mg} / \mathrm{kg}) 15 \mathrm{~min}$ before streptozotocin (65 mg/kg i.p) administration [10]. The streptozoticin (STZ) was freshly prepared by dissolving in $0.1 \mathrm{M}$ citrate buffer, $\mathrm{pH} 4.5$, and nicotinamide was prepared in normal saline. The blood glucose level was observed at $48 \mathrm{~h}$ interval and diabetes was confirmed when fasting blood glucose level had reached above $250 \mathrm{mg} / \mathrm{dl}$. As STZ is capable of inducing fatal hypoglycemia as a result of massive pancreatic insulin release, STZ-treated rats were provided with $10 \%$ glucose solution after 3 $\mathrm{h}$ for the next $24 \mathrm{~h}$ to prevent fatal hypoglycemia [11]. Different doses of the extract were selected on the basis of acute toxicity study.

\section{Experimental design}

Animals with blood glucose level above $250 \mathrm{mg} / \mathrm{dl}$ were selected and divided into six groups comprising six animals in each group.

Table 1: Diabetic animal groups

\begin{tabular}{ll}
\hline GROUP-I (Normal control) & Administered with normal saline \\
\hline GROUP-II (Standard drug treated) & Treated with metformin hydrochloride at $10 \mathrm{mg} / \mathrm{kg}$ body weight per orally for $15 \mathrm{~d}$ \\
GROUP-III (Negative control) & No treatment received \\
GROUP-IV (Low dose treated) & Treated with test extract at $100 \mathrm{mg} / \mathrm{kg}$ body weight per orally for $15 \mathrm{~d}$ \\
GROUP-V (Medium dose treated) & Treated with test extract at $200 \mathrm{mg} / \mathrm{kg}$ body weight per orally for $15 \mathrm{~d}$ \\
GROUP-VI (High dose treated) & Treated with test extract at $400 \mathrm{mg} / \mathrm{kg}$ body weight per orally for $15 \mathrm{~d}$ \\
\hline
\end{tabular}

Blood samples were collected from the tail vein of the overnight (1215h) fasted rats and blood glucose level was determined on 0th, 5th, 10 th and 15th day along with body weight and body temperature. On the 15th day, all the animals were sacrificed and evaluated for the biochemical parameters, histopathology of the pancreas tissue $[12,13]$. On the $15^{\text {th }}$ day of treatment, blood was collected from the animals and centrifuged at $4000 \mathrm{rpm}$ for $5 \mathrm{~min}$ to separate the serum. From serum, different biochemical parameters like total cholesterol, HDL, LDL, triglycerides, SGOT, SGPT, ALP and total protein levels in serum were measured colorimetrically.

\section{Statistical analysis}

The different data obtained from the experiment were expressed as mean \pm SD of six replicates and subjected to one-way analysis of variance (ANOVA) followed by Dunnet comparison all vs control method. Values were considered statistically significant at $\mathrm{p}<0.01$.

\section{RESULTS}

\section{Acute toxicity study}

As per calculations from acute oral toxicity (guideline 425) statistical program (version 1.0), the $\mathrm{LD}_{50}$ value of Cascabela thevetia L. bark extract was found to be more than $2000 \mathrm{mg} / \mathrm{kg}$ body weight. Hence one tenth of this dose was selected for calculations of doses using in the antidiabetic study.

Effect of methanolic bark extract on body weight, body temperature, and fasting blood glucose level

The effects of different doses $(100 \mathrm{mg} / \mathrm{kg}, 200 \mathrm{mg} / \mathrm{kg}$ and 400 $\mathrm{mg} / \mathrm{kg}$ body weight) of the methanolic bark extract of Cascabela thevetia L. on the fasting blood glucose level were investigated in the STZ induced diabetic Wistar albino male rats using metformin hydrochloride as standard drug (10 $\mathrm{mg} / \mathrm{kg}$ body weight), as a hypoglycemic agent. The divergence of body weights and body temperature of the animals was noted in tables 2 and 3 respectively. The mean blood glucose levels of controlled groups and test groups were noted as showed in table 4 on $0^{\text {th }}, 5$ th, 10 th, and 15 th day of treatment. The hypoglycemic effect was experiential in animals treated with methanolic bark extract of Cascabela thevtia L. From the data it was found that the body weight of the diabetic rats had decreased significantly $(\mathrm{p}<0.01)$ in comparison to the normal rats. But after treatment with standard drug and different doses of the test extract, the body weight improved significantly in comparison to the negative control group and reached nearly to their normal values. In the case of body temperature, it was found that there was no significant difference in body temperature among the groups during the treatment period. Regarding blood glucose level, in diabetic rats, there was significant elevation $(\mathrm{p}<0.01)$ of blood glucose levels after induction of diabetes. But after treatment with standard drug and different doses of the test extract, it was observed that there was a significant reduction in blood glucose level from the $10^{\text {th }}$ day of treatment in comparison to the negative control group.

\section{Effects of methanolic bark extract on plasma lipid profiles}

The effects of different doses (100 mg/kg, $200 \mathrm{mg} / \mathrm{kg}$ and 400 $\mathrm{mg} / \mathrm{kg}$ body weight) of methanolic bark extracts of Cascabela thevetia L. on different plasma lipid levels were estimated in STZ induced diabetic rats in comparison with metformin hydrochloride (10 mg/kg weight). The comparative values are shown in table 5 . 
From the data, it was found that the triglyceride, cholesterol, and LDL levels were increased significantly $(\mathrm{p}<0.01)$ and HDL level was decreased significantly $(\mathrm{p}<0.01)$ in diabetic animals in comparison to normal animals. But after the treatment with the standard drug and different doses test extracts levels were restored nearly to their normal values.

Table 2: The deviation of body weight (g) of the animals during the treatment of methanolic bark extract of Cascabela thevetia L. during $15 \mathrm{~d}$ of treatment

\begin{tabular}{llll}
\hline Treatment day & $\mathbf{0}^{\text {th }}$ day & $\mathbf{5}^{\text {th }}$ day & $\mathbf{1 0}^{\text {th }}$ day \\
\hline Group I Normal control & $100.67 \pm 4.03$ & $100.33 \pm 4.22$ & $104.00 \pm 3.57 \# \#$ \\
Group II Negative control & $79.00 \pm 3.36^{* *}$ & $81.00 \pm 1.78^{* *} \# \#$ & $82.00 \pm 0.89^{* *} \# \#$ \\
Group III Standard drug & $83.67 \pm 2.73^{* *}$ & $91.67 \pm 4.03^{* *}$ & $96.00 \pm 2.36^{* *}$ \\
Group IV (100 mg/kg) & $82.67 \pm 2.73^{* *}$ & $91.33 \pm 2.06^{* *}$ & $79.00 \pm 0.89^{* *} \# \#$ \\
Group V (200 mg/kg) & $76.67 \pm 1.36^{* *}$ & $81.67 \pm 2.58^{* *} \# \#$ & $104.00 \pm 2.68$ \\
Group VI (400 mg/kg) & $76.67 \pm 4.03^{* *}$ & $90.67 \pm 1.03^{* *}$ & $94.67 \pm 2.73^{* *}$ \\
\hline
\end{tabular}

Values are expressed as mean \pm SD (number of animals, $n=6$ ) significantly different at ${ }^{* *} \mathrm{p}<0.01$, using Dunnett Compare all vs normal control and at $\#$ \# $<0.01$, using Dunnett Compare all vs standard treated.

Table 3: The deviation of body temperature $\left({ }^{\circ} \mathrm{F}\right)$ of the animals during the treatment of methanolic bark extract of Cascabela thevetia $\mathrm{L}$. during $15 \mathrm{~d}$ of treatment

\begin{tabular}{llll}
\hline Treatment day & $\mathbf{0}^{\text {th }}$ day & $\mathbf{5}^{\text {th }}$ day & $\mathbf{1 0}^{\text {th }}$ day \\
\hline Group I Normal control & $97.06 \pm 0.22$ & $97.36 \pm 0.84$ & $97.17 \pm 0.31$ \\
Group II Negative control & $97.2 \pm 0.26$ & $96.93 \pm 0.34 \#$ & $97.00 \pm 0.24$ \\
Group III Standard drug & $98.2 \pm 0.38$ & $98.26 \pm 0.40$ & $98.00 \pm 0.24$ \\
Group IV (100 mg/kg) & $97.00 \pm 1.33 \#$ & $97.9 \pm 1.26$ & $97.67 \pm 1.64$ \\
Group V (200 mg/kg) & $97.33 \pm 0.65$ & $97.7 \pm 0.47$ & $98.26 \pm 0.54$ \\
Group VI (400 mg/kg) & $98.1 \pm 1.03$ & $97.96 \pm 0.90$ & $97.97 \pm 0.27$ \\
\hline
\end{tabular}

Values are expressed as mean \pm SD (number of animals, $n=6$ ) significantly different at ${ }^{* *} \mathrm{p}<0.01$, using Dunnett Compare all vs normal control and at ${ }^{\#} \mathrm{p}<0.05$, using Dunnett Compare all vs standard treated.

Table 4: The effect of methanolic bark extract of Cascabela thevetia L. on fasting blood glucose level on STZ induced diabetic rats

\begin{tabular}{llll}
\hline Treatment day & $\mathbf{0}^{\text {th }}$ day & $\mathbf{5}^{\text {th }}$ day & $\mathbf{1 0}^{\text {th }} \mathbf{d a y}$ \\
\hline Group I Normal control & $103.67 \pm 6.59$ & $103.00 \pm 4.77$ & $102.00 \pm 0.89 \# \#$ \\
Group II Standard control & $278.33 \pm 24.35$ & $225.67 \pm 25.95$ & $165.00 \pm 8.80^{* *}$ \\
Group III Negative control & $304.00 \pm 43.52$ & $315.00 \pm 25.98$ & $313.67 \pm 16.67^{* *} \# \#$ \\
Group IV $(100 \mathrm{mg} / \mathrm{kg})$ & $314.33 \pm 9.85$ & $257.33 \pm 13.45$ & $195.33 \pm 9.13^{* *} \# \#$ \\
Group V $(200 \mathrm{mg} / \mathrm{kg})$ & $290.00 \pm 24.19$ & $248.33 \pm 11.67$ & $186.67 \pm 7.71^{* * \# \#}$ \\
Group VI $(400 \mathrm{mg} / \mathrm{kg})$ & $297.00 \pm 38.02$ & $260.00 \pm 12.29$ & $194.00 \pm 13.97^{* *} \# \#$ \\
\hline
\end{tabular}

Values are expressed as mean \pm SD (number of animals, $n=6$ ) significantly different at ${ }^{* *} \mathrm{p}<0.01$, using Dunnett Compare all vs normal control and at ${ }^{\#} \mathrm{p}<0.05,{ }^{\# \#} \mathrm{p}<0.01$, using Dunnett Compare all vs standard treated.

\section{Effect of methanolic bark extract on serum biomarkers}

The effects of different doses $(100 \mathrm{mg} / \mathrm{kg}, 200 \mathrm{mg} / \mathrm{kg}$ and 400 $\mathrm{mg} / \mathrm{kg}$ body weight) of methanolic bark extracts of Cascabela thevetia L. on different serum biomarker levels were estimated in STZ induced diabetic rats in comparison with metformin hydrochloride $(10 \mathrm{mg} / \mathrm{kg}$ body weight). The comparative values are shown in table 6. From the data, it was found that different serum biomarkers like ALP, SGOT, SGPT and total protein were increased significantly $(\mathrm{p}<0.01)$ in the case of diabetic rats in comparison to the normal rats. But after treatment with standard drug and different doses of the test extract, the values were decreased significantly and reached nearly to the normal values.

\begin{abstract}
Histopathology of pancreas
On the $15^{\text {th }}$ day of treatment, the animals of each group are sacrificed and pancreases tissue was collected for histopathological studies. Pancreases tissues were stained with hematoxylin and eosin before observation under the microscope. Microscopical photographs of the pancreases tissues of different groups are shown in fig. 1. In the case of normal control, the islets cells and boundaries were clearly visible. In the standard control group, along with islets boundaries, partial necrosis and restored cellular integrity was also seen. In the negative control group, destructed islets cells were clearly visible. Besides fatty degeneration and destruction of central lobes were also seen. In the test extract treated groups, cell ballooning, coagulation due to necrosis, partial necrosis, blood clotting, and fatty degeneration were observed.
\end{abstract}

Table 5: Effects of methanolic bark extract on plasma lipid profiles (cholesterol, triglycerides, HDL and LDL) in STZ induced diabetic rats

\begin{tabular}{|c|c|c|c|c|}
\hline Groups & Triglyceride (mg/dl) & Cholesterol (mg/dl) & HDL (mg/dl) & LDL (mg/dl) \\
\hline Group I Normal control & $78.37 \pm 3.30$ & $92.47 \pm 3.92 \# \#$ & $54.23 \pm 2.72$ & $22.55 \pm 7.08$ \\
\hline Group II Standard control & $78.53 \pm 3.83$ & $79.72 \pm 2.19 * *$ & $51.53 \pm 1.04$ & $12.48 \pm 1.43$ \\
\hline Group III Negative control & $139.82 \pm 3.65^{* * \# \#}$ & $161.32 \pm 3.13^{* *}$ & $35.82 \pm 1.16^{* *} \# \#$ & $97.53 \pm 4.58^{* * \# \#}$ \\
\hline Group IV (100 mg/kg) & $124.68 \pm 4.14^{* * \# \#}$ & $157.27 \pm 6.93 \# \#$ & $38.61 \pm 4.41^{* * \# \#}$ & $93.98 \pm 11.78^{* * \# \#}$ \\
\hline Group V(200 mg/kg) & $103.50 \pm 7.31 * * \# \#$ & $88.73 \pm 8.26$ & $56.25 \pm 5.04 \#$ & $11.77 \pm 4.58$ \\
\hline Group VI(400 mg/kg) & $112.29 \pm 14.35^{* *} \# \#$ & $131.45 \pm 8.98^{* *} \# \#$ & $49.54 \pm 1.13$ & $59.44 \pm 8.81^{* *} \# \#$ \\
\hline
\end{tabular}

Values are expressed as mean \pm SD (number of animals, $n=6$ ) significantly different at ${ }^{* *}$ p $<0.01$, using Dunnett Compare all vs normal control and at ${ }^{\#} \mathrm{p}<0.05,{ }^{\# \#} \mathrm{p}<0.01$, using Dunnett Compare all vs standard treated. 
Table 6: Effect of methanolic bark extract on serum biomarkers in STZ induced diabetic rats

\begin{tabular}{lllll}
\hline Groups & ALP (U/l) & SGOT (U/l) & SGPT (U/l) & Total protein (g/dl) \\
\hline Group I Normal control & $44.83 \pm 5.78 \# \#$ & $54.19 \pm 4.16$ & $45.26 \pm 2.82$ & $4.38 \pm 0.45$ \\
Group IIStandard control & $61.72 \pm 4.58^{* *}$ & $47.74 \pm 6.10$ & $42.52 \pm 1.67$ & $4.08 \pm 0.72$ \\
Group III Negative control & $142.56 \pm 4.48^{* * \# \#}$ & $112.14 \pm 2.37^{* * \# \#}$ & $91.99 \pm 1.34^{* * \# \#}$ & $5.96 \pm 0.43^{* * \# \#}$ \\
Group IV (100 mg/kg) & $126.80 \pm 4.29^{* * \# \#}$ & $52.90 \pm 4.16 \#$ & $56.31 \pm 5.27^{* *} \# \#$ & $5.17 \pm 0.22^{* * \# \#}$ \\
Group V (200 mg/kg) & $80.94 \pm 7.19^{* * \# \#}$ & $49.03 \pm 5.76$ & $48.36 \pm 3.25 \#$ & $4.15 \pm 0.11$ \\
Group VI (400 mg/kg) & $99.96 \pm 7.85^{* * \# \#}$ & $58.06 \pm 5.76$ & $48.02 \pm 4.66 \#$ & $5.79 \pm 0.18^{* * \# \#}$ \\
\hline
\end{tabular}

Values are expressed as mean $\pm \mathrm{SD}$ (number of animals, $\mathrm{n}=6$ ) significantly different at ${ }^{* *} \mathrm{p}<0.01$, using Dunnett Compare all vs normal control and at $\#$ \# $<<0.01$, using Dunnett Compare all vs standard treated.

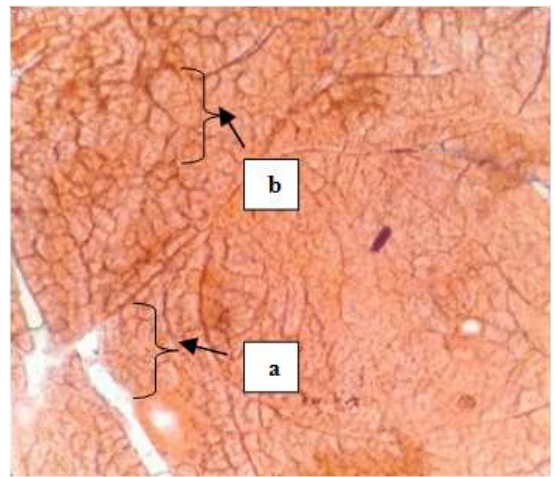

Group I (Normal control)

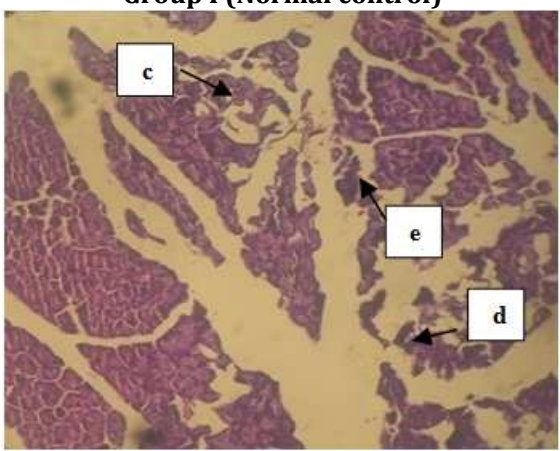

3) Group III (Negative control)

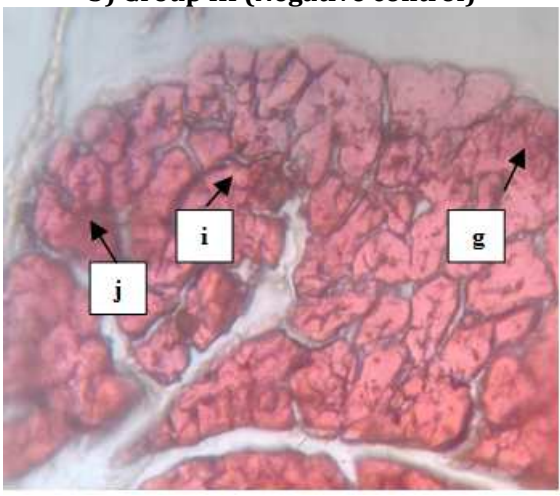

5) Group V (200 mg/kg body wt.)
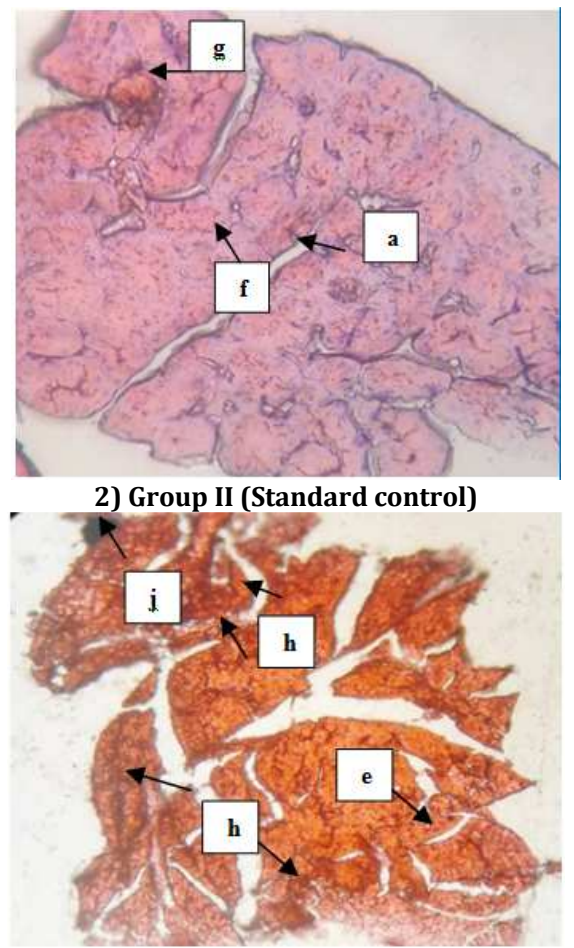

4) Group IV (100 mg/kg body wt.)

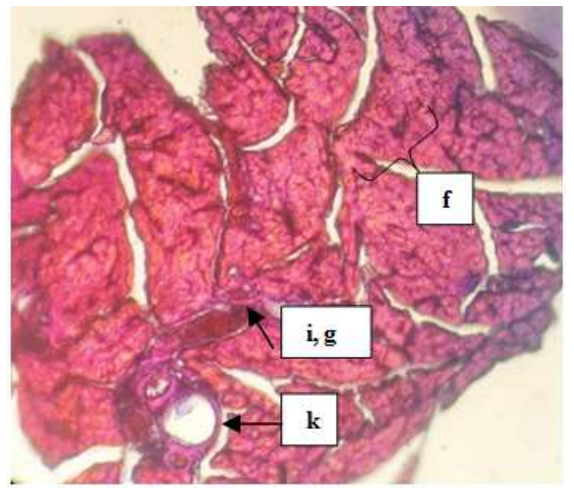

6) Group VI (400 mg/kg body wt.)

Fig. 1: Histoarchitecture of pancreas tissue treating with drug and test extracts, (a) clear islet boundaries (b) islet cells clearly visible, (c) destructed cells (d) destroyed central lobes, (e) fatty degeneration (f) restored cellular integrity, (g) partial necrosis (h) coagulation due to necrosis, (i) Slight cell ballooning (j) blood clotting or necrosis, (k) Cell ballooning

\section{DISCUSSION}

This study was conducted to confirm the traditional use of bark of Cascabela thevetia L. for the treatment of diabetes as reported in the ethnomedicinal documentation. The present study was carried out to investigate the acute toxicity and antidiabetic activity of the methanolic bark extract in an animal model to ratify their traditional use as a treatment for diabetes.
In this study, STZ-nicotinamide induced type 2 diabetic rat model was used. It is considered to be a type 2 model due to the partial destruction of $\beta$-cells of the islets of Langerhans in the pancreases. Type 2 diabetes mellitus is followed by a number of defects like impaired insulin secretion by the pancreatic $\beta$-cells, the resistance of peripheral tissues to the glucose utilizing the effect of insulin and augmented hepatic glucose production [14]. In this study, Metformin 
hydrochloride was used as the standard drug which is a very suitable drug for the treatment of type 2 diabetes [15].

In the study conducted, increased blood glucose levels and loss of body weight confirmed the induction of hyperglycemia by streptozotocin (STZ) and nicotinamide.

\section{The body weight, body temperature and fasting blood glucose} levels

In this, study the body weight of STZ induced diabetic rats decreased gradually which may be due to the reduction of insulin, which regulates protein synthesis and proteolysis in skeletal muscles [16]. But the animals of test groups showed signs of improvement in their body weights progressively during the long $15 \mathrm{~d}$ treatment along with the standard control group animals. With the progress of diabetes, the body weights usually decreased but the administration of the plant extract the decrease in body weights discontinued during the period of study. The blood glucose level of animals increased significantly after induction of diabetes, but after treatment with standard drug and different doses of test extracts, it was significantly improved which may be possible due to the preventive effect on STZ-mediated B-cell damage in diabetic rats and thereby increases insulin releases [17].

The body temperature of the animal groups during the study was not significantly varied during the study period.

\section{Plasma lipid profiles of the animals}

Insulin resistance leads to alteration of lipid metabolism in type 2 diabetes mellitus, which further causes lipoprotein abnormalities and cardiovascular disease in type 2 diabetic patients [17]. The most common lipid abnormalities are hypertriglyceridemia, hypercholesterolemia and reduction in HDL in the case of diabetes mellitus. Insulin resistance causes increase free fatty acid release from insulin resistant fat cells and promote more triglycerides production $[18,19]$. In the present study, in type 2 diabetic rat models, serum cholesterol, triglyceride levels were increased and HDL level was decreased in comparison to the normal groups. But after administration of metformin hydrochloride and different doses of test extracts, the levels were significantly improved in comparison to the negative control group. The occurrence of cardiovascular disease in type 2 diabetes patients mainly due to insulin resistance mediated hyperglycemia and dyslipidemia. Drugs like metformin diminish insulin resistance, control the hyperglycemia and abnormal lipid metabolism and hence it can be able to prevent diabetes mediated cardiovascular complication. But it has some adverse effects such as lactic acidosis, gastrointestinal disturbances, liver toxicity and cardiovascular risk $[20,21]$. Zhang et al. had reported similar restoration of serum lipid profile in type 2 diabetic rat model in their research work [22].

\section{Serum biomarkers of the animals}

In the type 2 diabetic rat model elevation of enzymes such as SGOT, SGPT ALP was observed which may be due to liver dysfunction [23, 24]. The protein level in the blood serum was also slightly increased which was not so significant. But on treatment with test extracts and standard drug, the levels of the elevated marker enzymes i.e. SGOT, SGPT, and ALP were reduced and restored almost near to normal values. Gogoi et al. had reported the restoration of different enzymes levels mentioned above in type 2 diabetic rat model in their research work [25].

\section{Histopathology of pancreases}

In fig 1 the photomicrographs of pancreatic section staining with hematoxylin and eosin were shown. In the pancreatic sections of the normal control group, the islet boundaries were clear and the profiles of the islet cells were clearly visible. No necrosis or fatty degeneration observed in normal rats. In pancreatic sections of diabetic control group completely destructed cells were observed. Besides ballooning, picnosis and necrosis also occurred. Fatty layer degeneration, loss of normal eco-structure, destruction of central lobes were destroyed, loss of normal cellular integrity was also observed in the pancreatic section of negative control rats. Due to necrosis irregular gap junctions appeared and coagulation occurred.
In the test group of low dose (100 $\mathrm{mg} / \mathrm{kg}$ body weight), partial necrosis and ballooning were observed. In the test group of medium dose $(200 \mathrm{mg} / \mathrm{kg}$ body weight), in most portions, cellular integrity was normal with slight fatty degeneration. In the test group of high dose, (400 mg/kg bodyweight), cellular integrity was normal to a great extent. Fatty degeneration in some portion was visible. In the standard treated group (10 $\mathrm{mg} / \mathrm{kg}$ body weight), cellular integrity was normal. Fatty layer degeneration had occurred along with slight ballooning, but no blood clotting or necrosis had been noticed. Histopathological studies of the pancreas in diabetic and treated groups substantiated the cyto-protective action of extract. From the preliminary phytochemical screening, we found many phytoconstituents like alkaloid, flavonoid, triterpenoid, tannin, phytosterol in the bark of Cascabela thevetia L. Some earlier works had already proved that these secondary plant metabolites could responsible for antidiabetic, hypoglycemic or antihyperglycemic activity [26]. From the above information, it can be stated that the antidiabetic activity of methanolic bark extract may sensitize the insulin receptor from beta cells of islets of Langerhans in the pancreas of STZ-induced diabetic rats and hence supported the in vivo antidiabetic status.

\section{CONCLUSION}

From the in vivo study, it was found that the bark extract of Cascabela thevtia L. able to reduce the blood glucose level and normalization of serum biochemical profile including lipid content as compared to negative control rats. From the preliminary phytochemical screening, we found many phyto-constituents like alkaloid, flavonoid, triterpenoid, tannin in the bark of Cascabela thevetia $\mathrm{L}$. which can be responsible for this activity as these class of compound have already proved for antidiabetic, hypoglycemic or antihyperglycemic activity. Further isolation of the compound(s) can lead to the discovery of the active chemical constituent and to understand the mechanism of action at the molecular level. From the study, it was cleared that the bark Cascabela thevetia L. had promising antidiabetic activity as documented claim, but furthermore, studies like molecular level and clinical level studies are required to establish its importance as a potent medicinal plant.

\section{ACKNOWLEDGEMENT}

The authors are thankful to the Department of Pharmaceutical Sciences, Dibrugarh University, Dibrugarh, Assam, India for providing the laboratory facilities to conduct the research work.

\section{CONTRIBUTION OF AUTHORS}

Both the authors had contributed equally to the research work

\section{CONFLICT OF INTERESTS}

\section{All authors have none to declare}

\section{REFERENCES}

1. Barcelo A, Rajpathak S. Incidence, and prevalence of diabetes mellitus in the America. Am J Public Health 2001;10:300-8.

2. Luzi L. Pancreas transplantation and diabetic complications. N Engl J Med 1998;339:115-7.

3. Gilman AG, Goodman LS. The pharmacological basis of therapeutics. $5^{\text {th }}$ ed. New York: Macmillan; 1985.

4. Spiller HA, Sawyer TS. Toxicology of oral antidiabetic medications. Am J Health Syst Pharm 2006;63:929-38.

5. WHO Expert Committee on Diabetes Mellitus: second report. World Health Organ Tech Rep Ser 1980;646:1-80.

6. Saravanamuttu S, Sudarsanam D. Antidiabetic plants and their active ingredients: a review. Int J Pharm Sci Res 2012;3:3639-50.

7. Khan MH, Yadava PS. Antidiabetic plants used in thoubal district of Manipur, North-East India. Indian J Tradit Know 2010;9:510-4.

8. Srivastava N, Chauhan AS, Sharma B. Isolation and characterization of some phytochemicals from indian traditional plants. Biotechnol Res Int 2012;1-8. http:// dx.doi.org/10.1155/2012/549850

9. Deshmukh V, Zade Z. Antifertility effect of aqueous, alcoholic and petroleum ether extract of Cascabela thevetia L. Fruit in female albino rats. Int J Pharm Biol Arch 2014;5:60-6.

10. Masiello P, Broca C, Gross R, Roye M, Manteghetti HD, Novelli RG. Experimental NIDDM: development of a new model in adult 
rats administered streptozotocin and nicotinamide. Diabetes 1998;47:224-9.

11. Rees DA, Alcolado JC. Animal models for diabetes mellitus. Diabet Med 2005;22:359-70.

12. Selvan VT, Manikandan L, Kumar SGP, Suresh R, Kakoti BB, Gomathi P, et al. Antidiabetic and antioxidant effect of methanol extract of Artanema sesamoides in streptozotocininduced diabetic rats. Int J Appl Res Nat Prod 2008;1:25-33.

13. Gazanfar K, Ganai BA, Akbar S, Khan M, Dar SA, Dar MY, et al. Antidiabetic activity of Artemisia amygdalina decne in streptozotocin-induced diabetic rats. BioMed Res Int 2014;110. http://dx.doi.org/10.1155/2014/185676

14. Shulman GI. Cellular mechanism of insulin resistance. J Clin Invest 2000;106:171-6.

15. Setter SM, Iltz JL, Thams J, Campbell RK. Metformin hydrochloride in the treatment of type 2 diabetes mellitus: a clinical review with a focus on dual therapy. Clin Ther 2003;25:2991-3026.

16. Castaneda C. Muscle wasting and protein metabolism. J Anim Sci 2002;80 Suppl 2:98-105.

17. Ramachandran S, Rajasekeran A, Adhiranjan N. In vivo and invitro antidiabetic activity of Terminalia paniculata barks: an evaluation of possible phytoconstituents and mechanisms for blood glucose control in diabetes. ISRN Pharmacol; 2013. p. 1-10.

18. Savage DB, Petersen KF, Shulman GI. Disordered lipid metabolism and pathogenesis of insulin resistance. Physiol Rev 2007;87:507-20.

19. Chehade JM, Gladysz M, Mooradian AD. Dyslipidemia in type 2 diabetes: prevalence, pathophysiology, and management. Drugs 2013;73:327-39.
20. Reaven G, Abbasi F, McLaughlin. Obesity, insulin resistance, and cardiovascular disease. Recent Prog Horm Res 2004;59:207-23.

21. Rang HP, Dale MM, Ritter JM, Flower R, Henderson G. Rang and Dale's Pharmacology. $8^{\text {th }}$ ed. Churchill Livingstone: Philadelphia; 2015.

22. Zhang J, Yao Y, Yin J, Zhou Q, Xu W. Anti-diabetic effects of polysaccharides from Talium triangulare in streptozotocin (STZ)-induced type 2 diabetes male mice. Int J Biol Macromol 2015;72:575-9.

23. Rao GM, Morghom LO, Kabur MN, Ben Mohmud BN, Ashibani K. Serum glutamic oxaloacetic transaminase (GOT) and glutamic pyruvic transaminase (GPT) levels in diabetes mellitus. Indian J Med Sci 1989;43:118-21.

24. Harris EH. Elevated liver function tests in type 2 diabetes. Clin Diabetes 2005;23:115-9.

25. Gogoi B, Kakoti BB, Borah S, Borah SN. Antihyperglycemic and in vivo antioxidative activity evaluation of Cinnamomum bejolghota (Buch.-Ham.) in streptozotocin induced diabetic rats: an ethnomedicinal plant in Assam. Asian Pac J Trop Biomed 2014;7 Suppl 1:427-34.

26. Gaikward SB, Mohan GK, Rani MS. Phytochemicals for diabetes management. Pharm Crop 2014;5 Suppl 1:11-28.

\section{How to cite this article}

- Neelutpal Gogoi, Biman Bhuyan. In vivo anti-diabetic activity evaluation of the bark of Cascabela thevetia L. in streptozotocin-induced diabetic rats. Int J Pharm Pharm Sci 2017;9(6):48-53. 